\title{
Efficiency Measurement of Supply Chain in the Export Frozen Vegetable Industry: A Network DEA Approach
}

\author{
W. Chaowarat and J. Shi
}

\begin{abstract}
Food and agricultural production in Thailand play an indispensable role in economic growth. The frozen vegetable industry is considered to be important due to its increasing annual exports. The goal of this paper is to measure the efficiency of export frozen vegetables using network DEA. We use the two-stage model to measures efficiency by separating the supply chain structure into suppliers and manufacturers. There are 12 criteria used for inputs and outputs. The results show that out of 8 organizations with supply chains, only 2 chains are efficient according to the BCC-O model and only 1 chain is efficient under the CCR-O model. However, if the manufacturer's role in the supply chain is considered, the results show that the majority of these manufacturers are efficient.
\end{abstract}

Index Terms-Network DEA, efficiency measurement, export frozen vegetable, supply chain.

\section{INTRODUCTION}

Food and agricultural production in Thailand play an essential role in economic growth because many local materials are used and many resources are brought in to develop the country's economy. This process benefits and develops the industry, brings export revenue into the country and facilitates investment in the industry. The frozen food industry is considered an important industry in Thailand because most frozen food is made from domestic agricultural products and meats, which can be transformed into many types of food. In Thailand, frozen vegetables are particularly important due to their export volume, which has increased annually in recent years [1].

In the frozen vegetable export industry in Thailand, competition is likely to intensify as a result of globalization, which makes trade freer and more open. Supply chain management (SCM) has emerged as the core strategy to build competitive advantage in this business, both nationally and at the local level.

Data envelopment analysis (DEA), which was pro- posed by Charnes, Cooper and Rhodes [2], is a technique based on linear programming (LP) that is used to mea- sure the relative efficiency of a set of decision-making units (DMUs) by measuring the efficiency of the $i$-th DMU relative to the others. This technique can be used with multiple outputs that are produced by each DMU.

In this study we will measure the efficiency of a frozen vegetable supply chain according to SCM using all members of the chain. The traditional DEA process, which consists of

Manuscript received December 5, 2012; revised January 10, 2013.

The authors are with the Division of Information and Electronic Engineering, Graduate School of Engineering at the Muroran Institute of Technology, Hokkaido, Japan (e-mail: Woramol.ch@gmail.com, shi@mmm.muroran-it.ac.jp). only one stage, cannot be used to evaluate highly complex structures. Thus, network DEA is proposed as a means to consider the internal structure of a DMU for two-or-more stage models.

The goal of this paper is to measure the efficiency of export frozen vegetables using network DEA. The two-stage model measures efficiency by separating the supply chain structure into two segments, suppliers and manufacturers, according to the structure of the Thai frozen vegetable supply chain. This methodology is used to show the efficiency of the supply chain.

\section{BACKGROUND LITERATURE}

\section{A. Supply Chain and Efficiency Measurement}

SCM is an integration and management technique for organizations that employ supply chain relationships and collaboration activities in building value-added products and services that are competitive and sustainable [3].

Supply chain efficiency is an overall efficiency mea- sure that depends on the efficiency of the stages in a supply chain [4]. The efficiency of a supply chain can be evaluated using information or feedback on the chain's activities and its success in meeting customer expectations and strategic objectives [5]. Supply china efficiency can also be understood as the degree to which the supply chain fulfills end-user requirements [6]. According to Neely [7], performance measurement is the process of quantifying the effectiveness and efficiency of actions.

Given the rapid pace of global change, efficiency measurement now plays an important role in SCM initiatives and improvement [8] because it helps decision maker to set objectives and goals, evaluate efficiency and determine future courses of actions. In recent years, efficiency measurement and indicators have received significant attention from researchers in many different fields.

\section{B. Data Envelopment Analysis}

Data envelopment analysis (DEA), which was introduced by Charnes et al [2], is an approach based on linear programming that assesses the relative performance of a set of production processes called decision-making units (DMUs). DEA examines the resources that are available to each unit and monitors the conversion of these resources (inputs) into the desired outputs [9]. The applications of DEA involve a wide range of contexts, including education, health care, banking, market research, retail outlets, organizational effectiveness, transportation, public housing, and manufacturing. In particular, DEA is a particularly excellent tool for improving the productivity of service businesses [10]. 
Variations on DEA are generally intended to customize the model to fit the application and to compensate for the inability of traditional DEA to evaluate highly complex structures. One representative study of serial systems was presented by Fare and Grosskopf [11], who first proposed the concept of network DEA. Complex systems typically consist of a number of sub- systems. These subsystems may form parallels, series, or networks. Different network DEA models have been proposed according to the type of relationship being evaluated [12]. Chen and Zhu [13] developed a model that ensures that the overall efficiency of a DMU requires each individual stage to be efficient.

\section{Methodology}

This section presents the research methodology used in this study. The following subsections offer an overview of a frozen vegetable supply-chain structure and the network DEA model that is used as the measure in this study.

\section{A. Overview of the Frozen Vegetable Supply-Chain Structure}

Drawing on the previous research conducted in related studies of the supply-chain concept, one can develop an overall picture of a frozen vegetable supply chain represented as in Fig. 1.

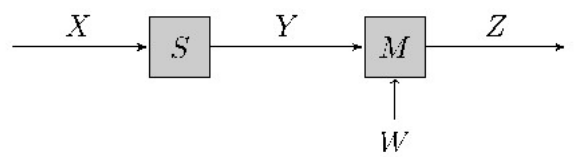

Fig. 1. The structure of a supply chain.

$S$ represents the main suppliers. In this chain, the main suppliers are the farmers with the contracted system. $M$ represents the manufacturer. $X$ the supplier's input and $Y$ is the supplier's output, which is also the manufacturer's input. $W$ is the manufacturer's input, which is not related to the supplier stage. $Z$ is the final output from the manufacturer. The $W, X, Y$ and $Z$ also serve as matrices in model (1)-(8) in the next subsection with elements $W_{l j}, X_{i j}, Y_{r j}$ and $Z_{k j}$, respectively.

TABLE I: THE CRITERIA IN THE MODEL

\begin{tabular}{|c|c|}
\hline Constructs & Criteria \\
\hline $\begin{array}{l}\text { Inputs for } \\
\text { Supplier(IS) }\end{array}$ & $\begin{array}{l}\text { IS1:Production Capacity } \\
\text { IS2:Ratio of Production Cost }\end{array}$ \\
\hline $\begin{array}{l}\text { Inputs for } \\
\text { Manufacturer(IM) }\end{array}$ & $\begin{array}{l}\text { IM1:Ratio of Production Cost } \\
\text { IM2:Ratio of Inventory \& Transportation Cost } \\
\text { IM3:Customer Contract Level }\end{array}$ \\
\hline $\begin{array}{l}\text { Intermediate } \\
\text { Products(IP) }\end{array}$ & $\begin{array}{l}\text { IP1:Supplier On-time Rate } \\
\text { IP2:Damage Rate } \\
\text { IP3:Supplier Contract Level }\end{array}$ \\
\hline Final Outputs(FO) & $\begin{array}{l}\text { FO1:Customer On-time Rate } \\
\text { FO2:Rate of Returned Products } \\
\text { FO3:Customer Complaints } \\
\text { FO4:Production Accuracy Rate }\end{array}$ \\
\hline
\end{tabular}

The inputs and outputs chosen for measurement are based on a review of the literature and interviews with experts in related fields of study. The criteria used for the inputs and outputs are presented in Table I, where $X i(i=1,2)$ stands for the $i$-th row of matrix $X, W l(l=1,2,3)$ the $l$-th row of matrix
$W, \operatorname{Yr}(r=1,2,3)$ the $r$-th row of matrix $Y, Z k(k=1, \ldots, 4)$ the $k$-th row of matrix $Z$.

\section{B. Network DEA Model}

In this paper, the model presented by Chen and Yan [14] is adapted by adding the manufacturer's inputs to evaluate efficiency. This model is based on the concept of decentralized management, in which component of a chain has its own decision maker who manages its own operations. Moreover, in agricultural production, uncontrollable factors can exert the greatest effects on productivity. Most of these uncontrollable factors affect the main supplier: farmers. It is therefore more feasible to control factors that are related to the manufacturer than it is to control those that are related to the suppliers. For this reason, we use an output-oriented in this paper.

Suppose that we have $J$ DMUs and the $o$-th DMU of them is the target on its efficiency that is interested. Note that $o \in$ $\{1, \ldots, J\}$. As a general case indicated in Fig. 1, we have $I$ suppliers who use the inputs $X$ to produce the quantity $R$ of intermediate products $Y$. After the intermediate products are produced, we use $L$ number of manufacturer inputs $W$ to produce a number of $\mathrm{K}$ number of final outputs $Z$. Based on the chosen criteria, the model can be structured as follows, where $\phi^{*}$ is the efficiency score of a chain (the optimal value to the programming in (1)-(8)), $\phi_{m}, \phi_{s}, \lambda_{j}^{1}, \lambda_{j}^{2}$ are variables and $X_{i j}, Y_{r j}, Z_{k j}, W_{l j}, w_{s}, w_{m}$ are the given data.

$$
\operatorname{maxzimize} \phi^{*}=w_{s} \phi_{s}+w_{m} \phi_{m}
$$

$$
\begin{array}{cc}
\text { subject to } \sum_{j=1}^{J} \lambda_{j}^{1} X_{i j} \leq X_{\text {io }} & i=1, \ldots, I \\
\sum_{j=1}^{J} \lambda_{j}^{2} Y_{r j}-\phi_{s} Y_{r o} \leq 0 & \mathrm{r}=1, \ldots, R \\
\phi_{s} Y_{r o}-\sum_{j=1}^{J} \lambda_{j}^{1} Y_{r j} \leq 0 & \mathrm{r}=1, \ldots, R \\
\sum_{j=1}^{J} \lambda_{j}^{2} W_{l j} \leq W_{l o} & l=1, \ldots, L \\
\phi_{m} Z_{k o}-\sum_{j=1}^{J} \lambda_{j}^{2} Z_{k j} \leq 0 & \mathrm{k}=1, \ldots, K \\
\lambda_{j}^{1}, \lambda_{j}^{2} \geq 0 & \\
\phi^{*}, \phi_{s}, \phi_{m}: \text { free } &
\end{array}
$$

$\phi_{m}$ : The efficiency score for the manufacturer.

$\phi_{s}:$ The efficiency score for the supplier.

$X_{i j}$ : The $i$-th supplier's inputs to the supplier for $j$-th 
DMU.

$Y_{r j}$ : The $r$-th intermediate products passed between the supplier and the manufacturer for the $\mathrm{j}$-th DMU.

$Z_{k j}:$ The $k$-th final outputs for the manufacturer for the j-th DMU.

$W_{l j}$ : The l-th manufacturer's inputs for the $j$-th DMU. $\lambda_{j}^{1}, \lambda_{j}^{2}$ : A dual variable utilized to construct to a composite ideal DMU to dominate the DMU under evaluation for the supplier and manufacturer, respectively.

$w_{s}$ : The given user-specific weight for the supplier and $w_{s}+w_{m}=1, w_{s} \geq 0, w_{m} \geq 0$.

$w_{m}$ : The given user-specific weight for the manufacturer and $w_{s}+w_{m}=1$.

$J$ : The number of DMUs.

$I$ : The number of supplier's inputs.

$R$ : The number of intermediate products.

$L:$ The number of manufacturer's inputs.

$K:$ The number of final outputs.

Objective function (1) assesses the efficiency scores of the chain. Constraint (2) certifies that the $i$-th supplier's inputs, according to the $o$-th DMU (DMUo), are greater than or equal to a linear combination of the $i$-th supplier's inputs for each j-th DMU (DMUj). Constraint (3) confirms that the optimal intermediate products are supplier's inputs and that the supplier's inputs $i$, according to DMUo, are greater than or equal to a linear combination of the inputs for each DMUj. Constraint (4) confirms that the optimal intermediate products are manufacturer outputs and that the outputs $i$ according to DMUo are less than or equal to a linear combination of the outputs for each DMUj. Constraint (5) states that the $i$-th manufacturer's inputs according to DMUo are more than or equal to a linear combination of the $i$-th manufacturer's inputs for each DMUj. Constraint (6) states that the optimal $k$-th final output, according to DMUo, is greater than or equal to a linear combination of the $k$-th final outputs for each DMUj. If the constraints $\sum_{j=1}^{n} \lambda_{j}^{1}=1$ and $\sum_{j=1}^{n} \lambda_{j}^{2}=1$ are included in model (1)-(8), it may be called as output-oriented BCC.

\section{RESUlTS}

In this paper, the datasets for the suppliers' inputs $X$, the intermediate products $Y$, the manufacturer's inputs $\mathrm{W}$ and the final outputs $Z$ were generated using 8 of the 56 manufacturers who are the members of the Thailand Institute of Scientific and Technological Research (TISTR), Food Technology Department. The interviewer with informant accordingly to the criteria for measuring efficiency in this study was observed to obtain the accurate information to collect all the data.

In this study, MATLAB is used to solve the network DEA model. The preliminary results obtained from the model in this study are presented in Table 2 . The specific weights of the suppliers and manufacturers are the same, i.e, $w_{s}=w_{m}=0.5$.
The model (1)-(8) has the following properties: if the efficiency score $\phi^{*}$ is equal to $1\left(\phi^{*}=1\right)$, then both $\phi_{m}$ and $\phi_{s}$ are equal to $1\left(\phi_{m}=1\right.$ and $\left.\phi_{s}=1\right)$. It shows that the DMUs can reach the maximum output using no more than the observed amount of any input. Conversely, if the efficiency score $\phi^{*}$ is greater than $1\left(\phi^{*}>1\right)$, then at least one of $\phi_{s}$ or $\phi_{m}$ is greater than 1 ( $\phi_{s}>0$ or $\phi_{m}>0$ ). Thus, the DMUs can increase their output using the same amount of input. In other words, the DMUs remain inefficient. In the BCC-O example, the both the supplier and the manufacturer for the first DMU (DMU1) have the efficiency score of 1 . This result indicates that both the supplier and the manufacture are efficient.

TABLE II: THE SUPPLy CHAIN EFFICIENCIES

\begin{tabular}{ccccccc}
\hline \multicolumn{3}{c}{ BCC-O } & \multicolumn{4}{c}{ CCR-O } \\
\hline DMUs & $\phi_{s}$ & $\phi_{m}$ & $\phi^{*}$ & $\phi_{s}$ & $\phi_{m}$ & $\phi^{*}$ \\
\hline 1 & 1 & 1 & 1 & 1 & 1 & 1 \\
2 & 1.013 & 1 & 1.007 & 1.003 & 1 & 1.007 \\
3 & 1 & 1.006 & 1.003 & 1 & 1.006 & 1.003 \\
4 & 1.005 & 1 & 1.003 & 1.005 & 1 & 1.003 \\
5 & 1.005 & 1.003 & 1.004 & 1.005 & 1.003 & 1.004 \\
6 & 1.003 & 1 & 1.002 & 1.003 & 1 & 1.002 \\
7 & 1 & 1 & 1 & 1.009 & 1 & 1.005 \\
8 & 1.005 & 1 & 1.003 & 1.005 & 1 & 1.003 \\
\hline
\end{tabular}

As Table II indicates, our measurements for the DMUs show that few of the supply chains are efficient. The results obtained using $\mathrm{BCC}-\mathrm{O}$ and $\mathrm{CCR}-\mathrm{O}$ methodologies are similar. Of the 8 DMUs, only DMU1 and DMU7 under the BCC-O model and DMU1 under the CCR-O model are efficient.

The overall efficiency score for a supply chain is a combination of the efficiency scores of the supply chain's suppliers and manufacturers. Thus, if a supply chain is effective, both its suppliers and its manufacturers will be efficient. In this study, after separately measuring by member type, we find that the suppliers, i.e., the farmers are the source of most of the inefficiency. Many of the suppliers have efficiency score of more than 1 . Of the 8 organizations, 5 and 6 DMUs are inefficient under BCC-O and CCR-O, respectively. However, if only the manufacturers units are considered, only 2 DMUs are inefficient, regardless of which methodology is used. The results show that most of the organizations are efficient and thus well managed.

These results suggest that other factors whose effects are largely uncontrollable may influence the farmers. One supplier input, production capacity, is also an example of an uncontrollable factor because farmers cannot entirely control the quality of soil. Furthermore, farmers' productivity depends on successful cultivation, which itself relies heavily on the farm's environment, including natural disasters, plagues, pests and even on labor variations in different regions. These factors generate differences in the numbers of workers and the convenience of shipments between farmers and factories. All of these factors affect the product quality, making it difficult to increase productivity even when efficient management practices are used.

When factories alone are considered, the efficiency levels are much higher than when farmers are also considered. In factories, efficient procedure can influence productivity because factory procedures can be controlled more easily. Furthermore, specific principles can easily be applied to 
factory processes to facilitate planning and mechanical functions, which, in turn, further productively.

\section{CONCLUSION AND IMPLICATION}

This study considers the current structure of supply- chain management for the export frozen vegetables in Thailand, primarily in Northern Thailand. The total inputs and outputs of each member of the chain were identified. Efficiency was measured using network DEA. The results show that almost all of the supply chains are inefficient. However, if only the manufacturers are evaluated, most of the supply chains are efficient; conversely, on the supplier side, most of the chains are inefficient due to the lack of supplier control over significant factors. For this reason, the overall performance remains inefficient.

Although this article presents a useful methodology based on DEA modeling for managers or decision makers to use in making reasonable decisions based on supply chain performance data, the limitations of this method should also be considered. The data used in this study are derived from a small sample, and the use of this sample may have generated more anomalies than a larger sample set would have generated. The inputs and outputs were determined from these measurements, largely based on scale and overall perspective. These will be remiss in certain conditions. Furthermore, in this paper, we assigned both members of the supply chain equal weights. Changing these weights might have changed the efficiency score. Future studies might use additional measures to increase the comprehensiveness of the model as a tool for measuring the efficiency of organizations of supply chains. Future research might also use a dynamic network model to consider the effect of time on efficiency or the effect of using different weights.

\section{REFERENCES}

[1] W. Chaowarat, "Performance measurement of supply chain management for export frozen food," M.S. thesis, Department of Industrial Engineering, Chiang Mai University, Chiang Mai, Thailand, 2011.

[2] A. Charnes, W. W. Cooper, and E. Rhodes, "Measuring the efficiency of decision making units," Europe Journal of Operations Research, vol. 2, pp. 429-444, 1978.
[3] R. B. Handfield and E. L. Nichols, Introduction to supply chain management, 1st ed. Prentice Hall, New Jersey, pp. 183, 1999.

[4] D. M. Lambert and M. C. Cooper, "Issues in supply chain management," Industrial marketing management, vol. 29, pp. 65-83, 2000.

[5] F. T. S. Chan and H. J. Qi, "An innovative performance measurement method for supply chain management," Supply chain management: An international journal, vol. 8, pp. 209-223, 2003.

[6] J. G. A. J. V. D. Vorst, "Effective food supply chains: Generating, modeling and evaluation supply chain scenarios," Wageningen University, Wageningen, 2000

[7] A. Neely, "The evaluation of performance measurement research: Developments in the last decade and a research agenda for the next," International journal of operations and production management, vol. 25, pp. 1264-1277, 2005.

[8] L. Xu, B. Ma, and R. Lim, "AHP based supply chain performance measurement system," in Proc. 12th IEEE International Conference on Emerging Technologies and Factory Automation, Greece, pp. 1308-1315, 2007.

[9] J. Zhu, Quantitative models for performance evaluation and benchmarking, 2nd ed, Worcester Polytechnic Institute Worcester, MA, USA, 2009.

[10] D. H. Sherman and J. Zhu, "Service productivity management: Improving service performance using data envelopment analysis," Springer Science, Boston, 2006.

[11] R. Fare and S. Grosskopf, "Network DEA," Socio-Economic Planning Sciences, vol. 34, pp. 35-49, 2000

[12] C. Yun et al., "Network data envelopment analysis efficiency measure to matrix-type organization with an application in input-output tables," African Journal of Business Management, vol. 6, pp. 6997-7004, 2012.

[13] Y. Chen and J. Zhu, "Measuring information technology's indirect impact on firm performance," Information Technology and Management, vol. 5, pp. 9-22, 2004.

[14] C. Chen and H. Yan, "Network DEA model for supply chain performance evaluation," European Journal of Operation Research, vol. 213, pp. 147-155, 2001.

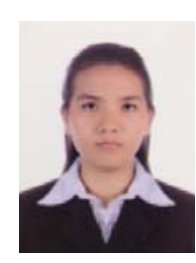

Chaowarat Woramol obtained her bachelor's degree from the Industrial Engineering Department, Faculty of Engineering, Khon Kaen University, Thailand in 2008, and her master's degree from the Industrial Engineering Department, Faculty of Engineering, Chiang Mai University in 2011. She is currently a Ph. D. student in the Graduate School of Engineering at Muroran Institute of Technology, Hokkaido, Japan. Her research is centered on the development of performance measurement systems for supply chains.

Jianming Shi is a professor in the Graduate School of Engineering at Muroran Institute of Technology (MuIT), Hokkaido, Japan. Prior to working at MuIT, he worked at Tokyo University of Science. His academic interests include mathematical programming and its applications, especially nonlinear optimization and global optimization. 